\title{
Reply to the correspondence on "Possible spontaneous PFO closure after thrombus trapped in PFO", Antonia Schulz et al., Clin Res Cardiol 2014; 103:333-335
}

\author{
Antonia Schulz • Franz Kleber
}

Published online: 13 June 2014

(c) Springer-Verlag Berlin Heidelberg 2014

\section{Sirs:}

We thank the authors for their important contribution. We briefly alluded to this pathophysiology in our discussion and regret that we have quoted the authors and not discussed this in more detail, simply because of constraints in space.

However, as the attached picture shows, the structure clearly protruded into the right atrial opening of the channel and was therefore not interpreted as a local thrombus formation. The different appearance of the right atrial opening before and after thrombus disappearance do underscore our interpretation.

This reply refers to the comment available at doi:10.1007/s00392014-0732-0.

This reply refers to the article available at doi:10.1007/s00392-0140732-0.

\footnotetext{
A. Schulz $(\bowtie) \cdot$ F. Kleber

Charité University Medicine Berlin, Berlin, Germany

e-mail: antonia.schulz@charite.de

F. Kleber

Cardio Centrum Berlin, Unter den Linden 21, 10117 Berlin,

Germany
}
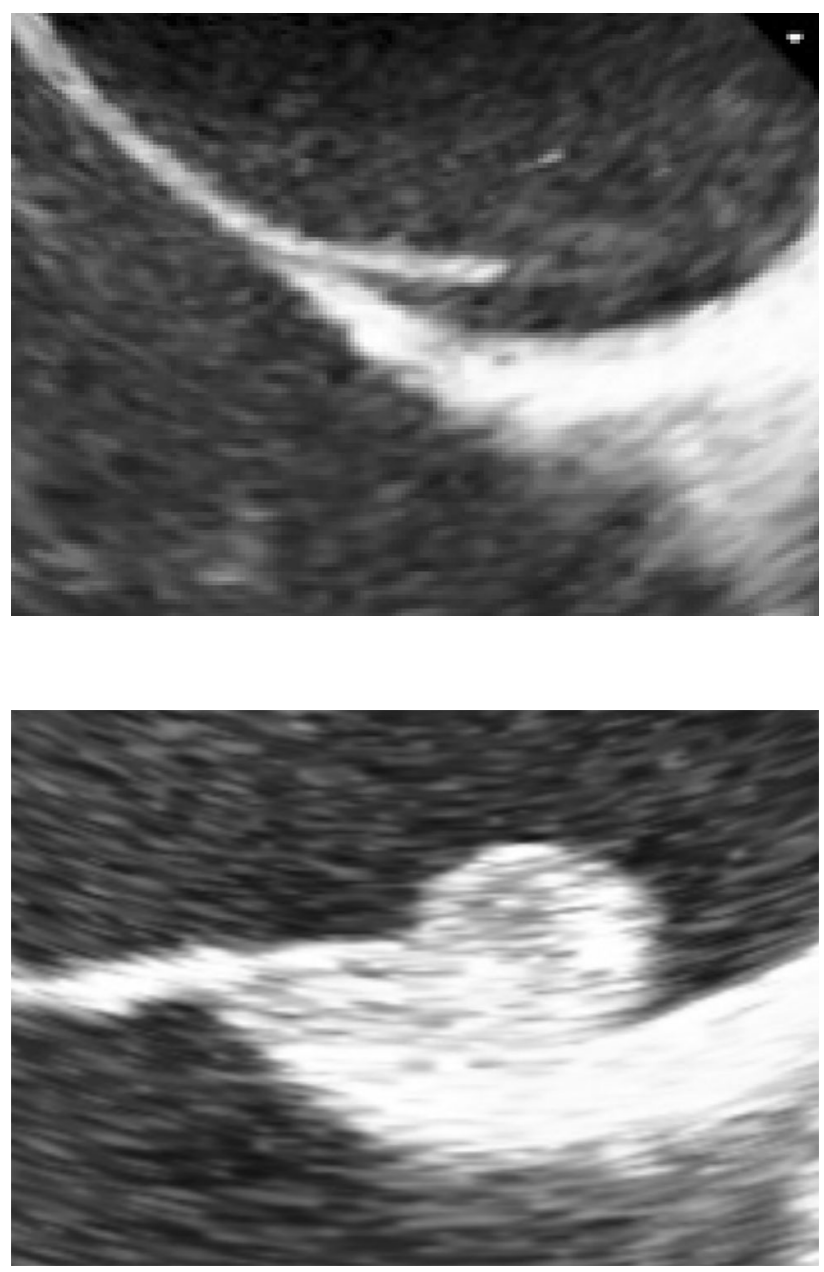